\title{
WALDO AS THE MEDIA TO TEACH ENGLISH TENSES
}

\author{
Andi Dian Rahmawan \\ Universitas PGRI Yogyakarta \\ ad.rahmawan@gmail.com
}

\begin{abstract}
In language teaching learning, teaching takes place as the primary activity. However, information about people's language ability can be acknowledged from a useful and necessary testing. This useful device is highly considered because having the knowledge of a language, which is one's linguistic competence is different to using this knowledge in actual production, which is one's linguistic performance. A test as a subset of assessment, in simple terms, is a method of measuring a person's ability, knowledge, or performance in given domain (Brown, 2004:3). Component of keywords related to this definition can be seen as (1) method - a set of techniques, procedures, or items that requires performance of the test-taker, (2) measure - to measure general ability, (3) individual's ability, competence and performance - to understand who the test-takers are and (4) domain - a sample that represents general competence.
\end{abstract}

\section{Introduction}

Several standardized tests of English proficiency are better known and commercially produced to Indonesian and international community, such as TOEFL $^{\circledR}$, MELAB, IELTS and TOEIC $^{\circledR}$ (Brown, 2004:84). The primary use of each test is various as job performance requirement or students seeking admission to English speaking universities. From specifications described by each test, which are considered as method of testing, four skills of receptive and productive English (reading-listening-speaking-writing) are common sections found in different type of test. While grammar as well as vocabulary cannot always be found as one special section to be tested in all tests, grammar competence is necessary for communication to take place as one of three dimensions of language (including semantics and pragmatics) that are interconnected (LarsenFreeman, 1991). No doubt that grammar is as prominence as other skills tested, therefore, it is often good to include a grammar component in the way of skill preformance test (Hughes, 1989:141-142).

$\mathrm{TOEFL}^{\circledR}, \mathrm{MELAB}$, and TOEIC ${ }^{\circledR}$ are some tests that specify grammar as one of part of the test in form of completing an incomplete sentence using one of four answers provided, identifying one of four underlined words or phrases that would not be accepted in English, multiple choice test containing grammar and error recognition. According to a pre-research done to one of TOEFL $^{\circledR}$ and TOEIC $^{\circledR}$ preparation distributed in Indonesia, a fact reveals that 70 to 80 percents of questions on grammar section contains problem on Subject-Verb Agreement. This indicates that grammar test based on Subject-Verb Agreement is essential to know learner's competence in grammar. However, this focus can be also frustrating by considering 16 tenses one should master in order to conquer this test section.

It is considered that there is an obligation to design one useful technique to ease the grammar test-taker or testee in test preparation class. Therefore, this research is important because it has two major purposes described as (1) to find a tehnique to ease testees in solving Subject-Verb Agreement problem and (2) to test the technique in order to measure its success to help testees. Focus of this Subject-Verb Agreement will take place around the main verb.

\section{Research Method}

Using researcher compentence in English grammar after years of studying and teaching this language, library research 
is conducted to design a new refreshed category of main verb accordingly to all tenses in English. This research is crutial to find the first purpose.

Technique used in this library research is inspired by kid's popular picture game - Where is Waldo? Waldo is described as a guy wearing a stripped redwhite costume and a big hat with the same motif. Waldo usually hides among crowd in various themes of pictures, such as beach, park, market or other potential crowded place. The purpose of the game is described in the game's name - to find Waldo. Main verb or MV in a sentence is considered as one word or phrase among many other words in the sentence and it can be tricky and challenging to find it. Therefore, it is important to find $\mathrm{MV}$ in order to solve the problem on Subject-Verb Agreement.

Then, with 50 respondents taken from the participant of TOEFL preparation class in one of Language Training Center in Yogyakarta, an experimental research is conducted to find the second purpose. 50 respondents are devided into two groups of controlled group and experimental group. The first group took 3 months of training without additional topic of new designed skill of finding MV and the later had several sessions to get accustomed with it. Data taken for this research is average improvement in score from pre-test and post-test of both groups.

\section{Finding and Discussion}

Referring to 16 tenses in English including simple present, simple past, present progressive, past progressive, present perfect, past perfect, future, present perfect continues, past perfect continues along with 6 other passive forms, MV can be categorized into 5 types of Waldo with 2 combinations between types.

\section{Category of Waldo}

\section{Waldo Type I}

Main Verb (MV) included to this category of Waldo Type I are (1) Verb I, (2) Verb I + -s/es, (3) Verb II (Verb I + -ed or Irregular Verbs) and (4) Auxiliary Verbs.

\section{$1.1 \quad$ Waldo Type I Verb I}

All of the verbs which the base form are not changed can be categorized into this type. This type of waldo is used in the Simple Present Tense which is attached to the first singular subject (I), the first plural subject (we), the second singular subject (you), the second plural subject (you) and the third plural subject (they).

The use of this type in sentence:

Some developers build new apartment complexes around our neighborhood.

\section{S $\quad$ MV = Waldo Type I (Verb I)}

1.2 Waldo Type I Verb I + -s/-es

Next, all of the verbs which function as predicate experience the alteration as the consequence of suffix -es or $-\mathrm{s}$. This alteration happens in Simple Present Tense which the subjects are the third singular woman (she), the third singular man (he) and the third singular thing, animal,plant (it).

The use of this type in sentence:

Unemployment influences the stability of Indonesian economic.

\section{S MV=Waldo Type I (Verb I + -s/-es)}

1.3 Waldo Type I Verb II (Verb I + -ed atau Irregular Verbs)

All of the verbs in Simple Past, both Regular and Irregular verbs, are included in this type.

The use of this type in sentence: 
Scientists from local university announced the finding of new medicine for cancer. S $\quad$ MV=Waldo Type I (Verb II $\rightarrow$ Verb I + -ed)

As part of their concern, some artists gave away donation to the flood victims.

S MV=Waldo Type I (Verb II $\rightarrow$ Irregular Verbs)

1.4 Waldo Type I Auxiliary Verbs

In a sentence which has no verb functions as predicate, a nominal sentence raises. The description of noun and adjective is raised. This is the reason the non-existance of the verb. It is stated that the Auxiliary verbs functions as predicate is important, and the kinds are indicated by the Subject and time. Known as Verb-Be or To-Be, what are categorized to this group including Am, Is, Are, Was and Were.

The use of this type in sentence:

The building $\underline{\underline{i s}}$ quite vulnerable to earthquake impact more than 6.5 scale of Richter

S MV=Waldo Type I (Aux for third singular Subject of Present Simple)

Candidate educational backgrounds are important for further consideration

S MW=Waldo Type I (Aux for plural)

Before the inaguration of the new director, work shift was not available for the staffs.

S MV=Waldo Type I (Aux for Past)

\section{Waldo Type II}

In this type, it is found that To-Be is attached to Verb I which is added by suffix -ing. Waldo type II To-be + Verb -ing is found in both Present and Past Progressive. The use of Verb -ing is dependent, which means that it can not stand alone if its existance functions as Waldo type II. For this reason, Verb -ing which is not preceded by To Be is not the Main Verb.

writing (Verb-Ing without To-Be) $\rightarrow($ (W)

$\ldots$ is/am/are writing (Verb-Ing preceeded by To-Be in Present Tense) $\rightarrow$ (MV)

$\ldots$ was/were writing (Verb-Ing preceeded by To-Be in Past Tense) $\rightarrow$ (MV)

The use of this type in sentence:

Dee, the author of Dealova, is writing her new book this year.

S MV=Waldo Type II (To-Be Present Progressive)

All participants were listening to the test recording carefully.

S MV=Waldo Type II (To-Be Past Progressive)

\section{Waldo Type III}

The following category MV is the verb used in Perfect sentence. The use of Auxiliary has or have or had which is attached to Verb III becomes the characteristics of Present and Past Perfect. Waldo type 4 emphasizes that Verb III can not stand alone. In this MV category, verb III can not rise in a sentence pattern without preceded by the auxiliary.

taken (Verb-III without has/have/had) $\rightarrow$ (

... has/have taken (Verb-III preceeded by Auxiliary Present Perfect Tense) $\rightarrow$ (MV)

... had taken (Verb-III preceeded by Auxiliary Past Perfect Tense) $\rightarrow$ (MV)

The use of this type in sentence:

So far, the committe members have had three candidates for director candidate.

S MV: Waldo Type III (have V3 $\rightarrow$ Present Perfect)

Our senior purser had flew to many countries before she resigned last June.

S MV: Waldo Type III (had V3 $\rightarrow$ Past Perfect) 


\section{Waldo Type IV}

If a sentence contains modal verbs, then this verb should be followed by a verb I. This is the criteria of the next Waldo type IV Modal + Verb I. Among of those modal verbs are can, could, may, might, will, would, shall, should and must. Other modal with different forms are ought to, have to and need to. Therefore, a modal verb followed by other than Verb I cannot be considered as MV.

can working (Modal followed by $\mathrm{V}$-ing) $\rightarrow($ ( $)$

may started (Modal followed by V-ed) $\rightarrow$ (

shall gone (Modal followed by V3) $\rightarrow($ ( $)$

$\ldots$ could come (Modal followed by V1 $\rightarrow$ simple past $) \rightarrow(\mathrm{MV})$

$\ldots$ have to go (Modal followed by V1) $\rightarrow(\mathrm{MV})$

The use of this type in sentence:

The principal will probably arrive at about 9 o'clock in the evening.

S $\quad \mathbf{M V}=$ Waldo Type IV (will V1 $\rightarrow$ future)

Everyone must stop whenever the traffic light turns red.

S MV=Waldo Type IV (must V1)

\section{Waldo Type $\mathbf{V}$}

To understand Waldo type V To-Be + Verb III, it is important to remember the structure of passive voice which the characteristics are (1) there is object in a sentence which positions as Subject (the discussion of the talk) and (2) there is a verb which has meaning that something is done to the object by the subject. This type of Waldo has the structure To Be + Verb III. The verb III can not stand alone without To-Be, as we can see in the verb -ing which can not stand alone if it functions as MV. It can be stated that Verb III which is not preceded by To Be is not an MV.

written (Verb-III tanpa To-Be) $\rightarrow$ (MV)

... is/am/are written (Verb-III is preceded by To-Be in Present Tense) $\rightarrow$ (MV)

... was/were writen (Verb-III is preceded by To-Be in Past Tense) $\rightarrow$ (MV)

Misunderstanding can occur in understanding "dependency" of the verb III. It is caused by the form of verb III in English which is oftenly has the same form with the verb II which is more independent. However, among verb III which has different form with verb II, this difference is clearly seen. For example, the verb II of 'wrote' and the verb III 'written' are clearly seen differently compared to the verb II 'bought' and the verb III 'bought". To differenciate it, check the existance of To-Be which precedes the word.

The use of this type in sentence:

The hall was cleaned thoroughly for this weekend event.

S MV=Waldo Type V (Aux + V3)

The wine is opened about three hours before the celebration.

S MV=Waldo Type V (Aux + V3)

\section{Possible Combination Between Each Waldo}

Beside all type of Waldo described above, there are also two other types which are resulted from combination between Waldo. They are:

1. Passive form of Modal + V1 (Aux) + V3

This is type of Waldo Type IV Modal + V1 combined with Waldo Type V Aux + V3. Auxiliary used for this type is be. Be as an auxiliary can be considered as verb 1 , therefore it fits the structure of Waldo Type V Aux + V3

The use of this type in sentence:

Ann will be invited as honorable guess in Bill's party next week. 


\section{S Modal V1 (aux) V3}

\section{Passive form of have/has/had $+\mathrm{V} 3+\mathrm{V} 3$}

Another form of passive sentence can be described by this combination of Waldo Type III have/has/had + V3 (aux) combined by Waldo Type V Aux + V3. Auxiliary used for this type is been which can be categorized as verb 3 of be. Therefore it won't violate both Waldo Type III as well as Waldo Type V.

The use of this type in sentence:

The final paper has been done exactly 3 hours before the time limit.

\section{$\mathrm{S} \quad$ has V3 (aux) V3}

\section{Impact of Waldo Session in Test Score Improvement}

Pre-test is conducted toward all participants who are going to attend TOEFL preparation test. Result of this test is a major factor in dividing participants into several classes consisting 25 people per each class. Next, a three month session is conducted to prepare all participants. After the session, a post-test is conducted to find the final score. Divided into two classes of controlled and experimental class, controlled class consists of those with 25 highest score from the pre-test while experimental class consists of those with 25 lowest score.

After several sessions with Waldo topic for the experimental class and regular session for the controlled class, scores of grammar test from pre-test and post-test of both classes are compared. Focus of the measure of this score takes place on the improvement of the score from pre-test to the post-test. Therefore, score from the post-test minuses score from the pre-test. From the data collected, average number from the improvement score of controlled class equals with 6,96 while from the experimental class, average number from improvement score equals with 7,04. This is an interesting finding because regardless the catagorizing of the class using highest versus lowest score in pre-test, the average score of improvement from pre-test to posttest is better for the experimental class than controlled class. This proves that Waldo session for grammar session preparation gives better improvement to the score.

\section{Conclusion}

Proficiency test is important to measure learner's competence in English. Among some well known standardized tests, it is found that grammar is prominence as an integrated section to be tested along with 4 English skills of reading, listening, speaking and writing. However, problem occurs in Subject-Verb Agreement focus in grammar test especially related to the finding of main verb. By categorizing 16 tenses into 5 types of Waldo, participant of test preparation class are able to improve their score in grammar section higher compared to those who didn't have Waldo training session.

\section{References}

Brown, H. Douglas. (2004). Language Assessment: Principles and Classroom Practices. New York: Pearson Education (1994). Teaching by Principles: An Interactive Approach to Language Pedagogy. London: Prentice Hall

Fromkin, Victoria and Robert Rodman. (2004). An Introduction to Language. 5th edition. New York: Harcourt Brace College Publishers.

Hughes, Arthur. (1989). Testing for Language Teachers. Cambridge: Cambridge University Press.

Larsen-Freeman, Diane. (1991). "Teaching Grammar." In Celce-Murcia, Marianne (Ed), Teaching English as a Second or Foreign Language. Second Edition. Newbury House. 